Article

\title{
Luminal lncRNAs Regulation by ER $\alpha$-Controlled Enhancers in a Ligand-Independent Manner in Breast Cancer Cells
}

\author{
Valentina Miano ${ }^{1,2,+}$, Giulio Ferrero ${ }^{1,2,3,+} \mathbb{B}^{\mathbb{D}}$, Valentina Rosti ${ }^{2, \ddagger}$, Eleonora Manitta ${ }^{2, \S}$, \\ Jamal Elhasnaoui ${ }^{1,2}$, Giulia Basile ${ }^{4}$ and Michele De Bortoli 1,2,* (D) \\ 1 Center for Molecular Systems Biology, University of Turin, Orbassano, 10043 Turin, Italy; \\ valentina.miano@unito.it (V.M.); giulio.ferrero@unito.it (G.F.); elhasnaouij@gmail.com (J.E.) \\ 2 Department of Clinical and Biological Sciences, University of Turin, Orbassano, 10043 Turin, Italy; \\ rosti@ingm.org (V.R.); eleonora.manitta@gmail.com (E.M.) \\ 3 Department of Computer Science, University of Turin, 10149 Turin, Italy \\ 4 Italian Institute for Genomic Medicine (IIGM), 10126 Turin, Italy; giulia.basile@iigm.it \\ * Correspondence: michele.debortoli@unito.it; Tel.: +39-0116-7050-58 \\ + These authors contribute equally to the work. \\ $\ddagger$ Current address: Istituto Nazionale di Genetica Molecolare INGM, 20122 Milan, Italy \\ $\S$ Current address: Novo Nordisk Foundation, Center for Basic Metabolic Research, Faculty of Health and \\ Medical Sciences, University of Copenhagen, DK-2200 Copenhagen, Denmark
}

Received: 29 December 2017; Accepted: 14 February 2018; Published: 16 February 2018

\begin{abstract}
Estrogen receptor- $\alpha(E R \alpha)$ is a ligand-inducible protein which mediates estrogenic hormones signaling and defines the luminal BC phenotype. Recently, we demonstrated that even in absence of ligands $\mathrm{ER} \alpha(\mathrm{apoER} \alpha)$ binds chromatin sites where it regulates transcription of several protein-coding and lncRNA genes. Noteworthy, apoER $\alpha$-regulated lncRNAs marginally overlap estrogen-induced transcripts, thus representing a new signature of luminal BC genes. By the analysis of H3K27ac enrichment in hormone-deprived MCF-7 cells, we defined a set of Super Enhancers (SEs) occupied by apoER $\alpha$, including one mapped in proximity of the DSCAM-AS1 lncRNA gene. This represents a paradigm of apoER $\alpha$ activity since its expression is largely unaffected by estrogenic treatment, despite the fact that E2 increases ER $\alpha$ binding on DSCAM-AS1 promoter. We validated the enrichment of apoER $\alpha$, p300, GATA3, FoxM1 and CTCF at both DSCAM-AS1 TSS and at its associated SE by ChIP-qPCR. Furthermore, by analyzing MCF-7 ChIA-PET data and by $3 \mathrm{C}$ assays, we confirmed long range chromatin interaction between the SE and the DSCAM-AS1 TSS. Interestingly, CTCF and p300 binding showed an enrichment in hormone-depleted medium and in the presence of $E R \alpha$, elucidating the dynamics of the estrogen-independent regulation of DSCAM-AS1 expression. The analysis of this lncRNA provides a paradigm of transcriptional regulation of a luminal specific apoER $\alpha$ regulated lncRNA.
\end{abstract}

Keywords: lncRNA; super enhancer; estrogen receptor; breast cancer

\section{Introduction}

Estrogen Receptor $\alpha(E R \alpha)$ is the key transcriptional factor of the luminal breast cancer subtype, which comprises three quarter of breast cancer cases [1], by mediating estrogen signaling in breast cancer cells. Nowadays, current endocrine treatments that block estrogen action include Selective Estrogen-Receptor Modulators (SERMs), Fulvestrant (pure anti-estrogen that degrades ER $\alpha$ protein) and Aromatase Inhibitors (AI) [2]. SERMs are synthetic compounds that function as agonists or antagonists for estrogen receptors in a tissue-specific manner. The first SERM that has been used successfully in the clinic is tamoxifen (TAM) which functions as cell type-specific anti-estrogens [3]. 
The most common endocrine treatments today are AIs, which block the biosynthesis of estrogens [4]. However, this therapy fails in one-fourth of $\mathrm{ER} \alpha+$ breast cancer cases because of de-novo or acquired endocrine resistance, which is generally characterized by accelerated tumor growth and increased aggressive behavior [5].

$\mathrm{ER} \alpha$ regulates biological processes in breast cancer cells by ligand-dependent (estrogen-ER $\alpha$ complex) or ligand-independent action (apoER $\alpha)$ [6]. Whereas estrogen dependent signaling was deeply studied in the last decades [7], few works were based on understanding apoER $\alpha$ mechanism in BC. It was reported that apoER $\alpha$ acts in cooperation with FOXA1 and AP2 $\gamma$ to maintain the luminal epithelial enhancer landscape and when one of these factors are suppressed, enhancers progressively collapse [6]. As previously demonstrated for E2-bound ER $\alpha$ genomic action [8], gene expression regulation by apoER $\alpha$ seems dependent on long range interaction between apoER $\alpha$-bound enhancers and promoters.

Recently, Super-Enhancers (SEs) emerged as a novel class of distal cis regulatory elements, defined as large clusters of putative enhancers in close genomic proximity which drive gene expression to define cell lineage identity [9]. SEs tend to span large genomic regions with unusually strong enrichment of lineage-specific TFs and co-activators binding. These stitched enhancers have additive and synergistic functions allowing them to drive high levels of tissue-specific gene expression. Commonly, SEs were predicted by identification of genomic regions enriched in H3K27ac ChIP-Seq signal compared to input or control experiment [10]. SEs represent the core of the transcription regulation for cell-type-specific gene expression and play a key role in cellular development and dynamic response to environmental stimuli [11,12]. Deciphering the active SEs in a specific context is helpful for the identification of key cis-regulation of coding and non-coding genes expression [13]. In MCF-7 cells, it was recently demonstrated that ER $\alpha$ is required for SEs formation upon binding to canonical response elements and in presence of FoxA1 pioneering factor [14]. This study elucidated SEs assembly in an estrogen-dependent manner, but the mechanism of SEs modulation by ligand-independent ER $\alpha$ remains unclear.

A full collection of lncRNAs has emerged during the last decade, stressing on their importance as regulators of cellular development and differentiation. They are expressed at lower levels than protein-coding transcripts, but compared to the latter, their pattern of expression is remarkably cell type-specific $[15,16]$. Indeed, to achieve a comprehensive annotation, lncRNAs expression has been quantitatively analyzed in several tissues and cell types by high-throughput RNA sequencing (RNA-seq) [17]. In BC research, lncRNAs have been involved in regulation of mammary epithelial cells homeostasis [18] and several studies focused on lncRNAs regulated by estrogen $[8,19,20]$. Finally, we recently identified for the first time a set of apoER $\alpha$-regulated lncRNAs [21]. Comparison with publicly available data showed that these lncRNAs are highly specific for the luminal BC subtype and therefore very promising in defining peculiar BC features. Among this set, DSCAM-AS1 is the most abundantly expressed lncRNA in BC cell lines and tissue samples. Expression of DSCAM-AS1 has a very peculiar dependence over ER $\alpha$ : the increased ER $\alpha$ binding at DSCAM-AS1 promoter upon estradiol stimulus does not lead to a concordant up-regulation of gene transcription over at least $24 \mathrm{~h}$ indicating a necessary and sufficient apoER $\alpha$ action for the regulation of DSCAM-AS1 transcription [21]. It has been reported that ER $\alpha$ binding to DSCAM-AS1 promoter is high in tumor tissues from patients unresponsive to Tamoxifen treatment and that DSCAM-AS1 expression is upregulated in Tamoxifen-resistant cellular models [22], contrary to typical estrogen-responsive genes that are strongly downregulated. These results suggest that actually distal putative enhancer or SE regions might be responsible for this peculiar transcriptional regulation and might be more generally involved in transcriptional regulation of cell-specific lncRNAs.

In the present study, we extended the analysis of apoER $\alpha$-regulated transcriptome in MCF-7, characterized apoER $\alpha$ binding at SEs (SE-aERBSs) and defined apoER $\alpha$-regulated lncRNAs that are associated and regulated by SE activation. In particular, we focused our attention on DSCAM-AS1 associated $\mathrm{SE}$ which is stabilized in a hormone-independent manner and whose regulation depends on 
the presence of apoER $\alpha$. It represents a paradigmatic example of how luminal lncRNAs are regulated by specific SEs activated through unliganded $E R \alpha$, which is extremely important to understand luminal breast tumor growth and progression, in view of the fact that common endocrine treatments today (AIs) deplete the organism of estrogenic hormones.

\section{Results}

\subsection{A Comprehensive List of apoER $\alpha$ Regulated Genes through SE Binding}

To define a comprehensive set of apoER $\alpha$ gene targets, we performed a long RNA-Seq analysis in triplicate of MCF-7 cultured in Hormone Deprived medium (HD) for $96 \mathrm{~h}$ and transfected with control siRNA (siCTR) or against ER $\alpha(\operatorname{siER} \alpha)$. Differential expression analysis revealed a set of 2487 differentially expressed (DE) coding and non-coding genes of which 1376 were down-regulated and 1110 up-regulated upon ER $\alpha$ silencing (Supplementary Table S1). Excluding ESR1, the most significant down-regulated protein coding genes were CALCR, ARL1, and TFF1 while KLF6, ZNF469, and TP53INP1 were the most significant up-regulated protein coding genes (Figure 1a). We identified also 317 DE lncRNAs of which 128 up-regulated and 189 down-regulated by ER $\alpha$ silencing. The most significant down-regulated lncRNAs were RP11-68L18.1, MIR9-3HG, and LINC01016, whereas NKILA, AC144831.1, and LINC00657 were the most significant up-regulated lncRNAs (Figure 1b).

Functional enrichment analysis of biological processes for the DE genes evidenced mitotic cell cycle (GO:0000278), mitotic nuclear division (GO:0007067), and cell cycle phase transition (GO:0044770) as the most enriched processes (Supplementary Table S2). Interestingly, different processes were enriched when up-regulated and down-regulated genes were considered separately. Specifically, siER $\alpha$ up-regulated genes were enriched for neuron projection guidance (GO:0097485), axon guidance (GO:0007411), and epithelium development (GO:0060429) while down-regulated genes were enriched for cell cycle- and DNA replication-related processes (Figure 1c).

To correlate apoER $\alpha$ genomic Binding Sites (aERBS) with gene regulation, we took advantage from our ER $\alpha$ ChIP-seq experiment performed in hormone-deprived MCF-7 cells [6]. As previously reported [6,21], analysis of apoER $\alpha$ binding mapped within $100 \mathrm{Kbp}$ from a DE gene TSS revealed a clear bias in receptor binding close to down-regulated as compared to up-regulated genes (Supplementary Figure S1a). Specifically, 485 down-regulated genes (35.2\%) compared to 300 up-regulated genes (27.0\%) were associated to an apoER $\alpha$ Binding Site (aERBS).

To verify whether the apoER $\alpha$ binding involved in DE gene regulation occurs within SEs in MCF-7 cells, we have applied a bioinformatics strategy that is summarized in Supplementary Figure S1b. In detail, starting from H3K27ac ChIP-seq data of MCF-7 cultured in HD medium for $48 \mathrm{~h}$ and treated with "vehicle" as control for E2 treatment (GSE40129) [23], we predicted 438 SEs (Supplementary Table S3) characterized by a significant and wide H3K27ac enrichment as previously reported [24]. Then, we associated SE to the first proximal gene TSS and we ranked SEs based on the H3K27ac/input enrichment. Interestingly, among the top 50 SEs associated with the highest H3K27ac signal, we found pivotal luminal BC protein-coding genes, including ESR1, GATA3, and FOXA1. Furthermore, lncRNA genes were also associated with this SEs set, including MALAT1 and DSCAM-AS1.

A subset of 227 SEs showed an overlap with aERBSs, hereafter referred to as "SE-aERBS". Considering the DE genes mapped within $100 \mathrm{kbp}$ from a SE-aERBS center, we associated $117 \mathrm{DE}$ genes including protein coding genes like ESR1, SPDEF, ZNF217, and RARA (Supplementary Table S4). 35 lncRNA genes were also associated to an SE-aERBS and they were subdivided in the following biotypes: 17 antisense, 9 lincRNAs, three processed pseudogenes, two processed transcripts, two transcribed unprocessed pseudogenes, one snoRNA, and one IncRNA lacking experimental evidence but annotated in Gencode database (To be Experimentally Confirmed, TEC). Interestingly, 77\% of DE genes associated to an aERBSs-SE were down-regulated upon apoER $\alpha$ silencing. 


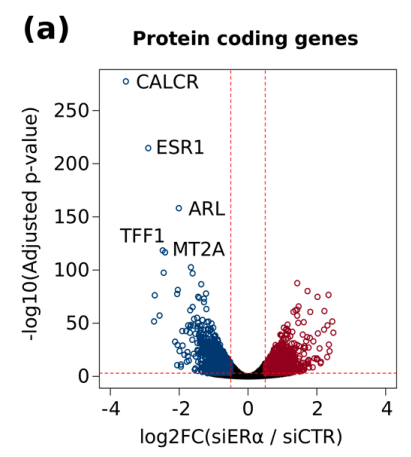

(d)

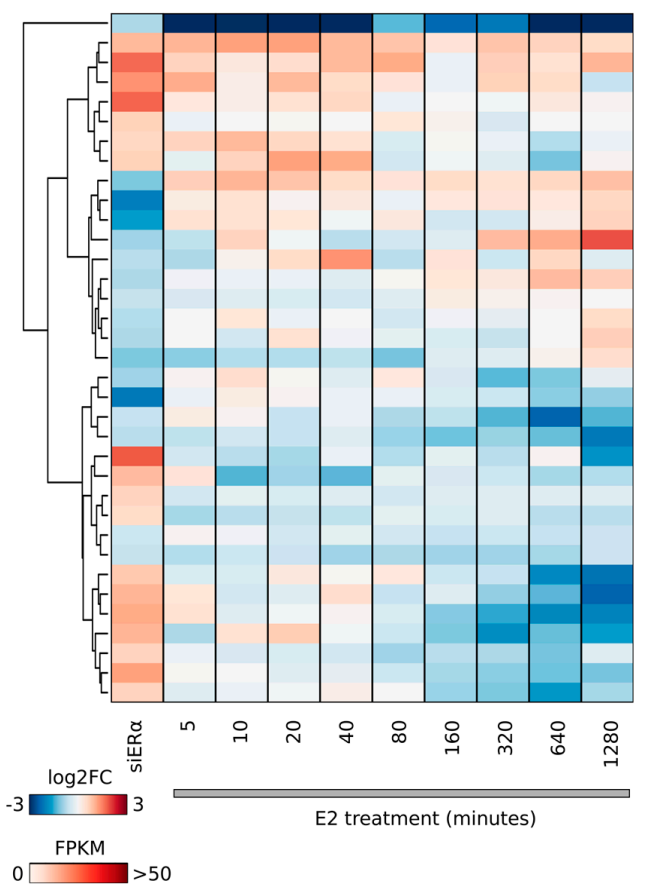

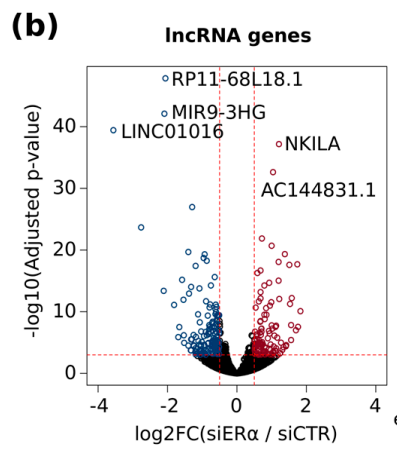

(e)
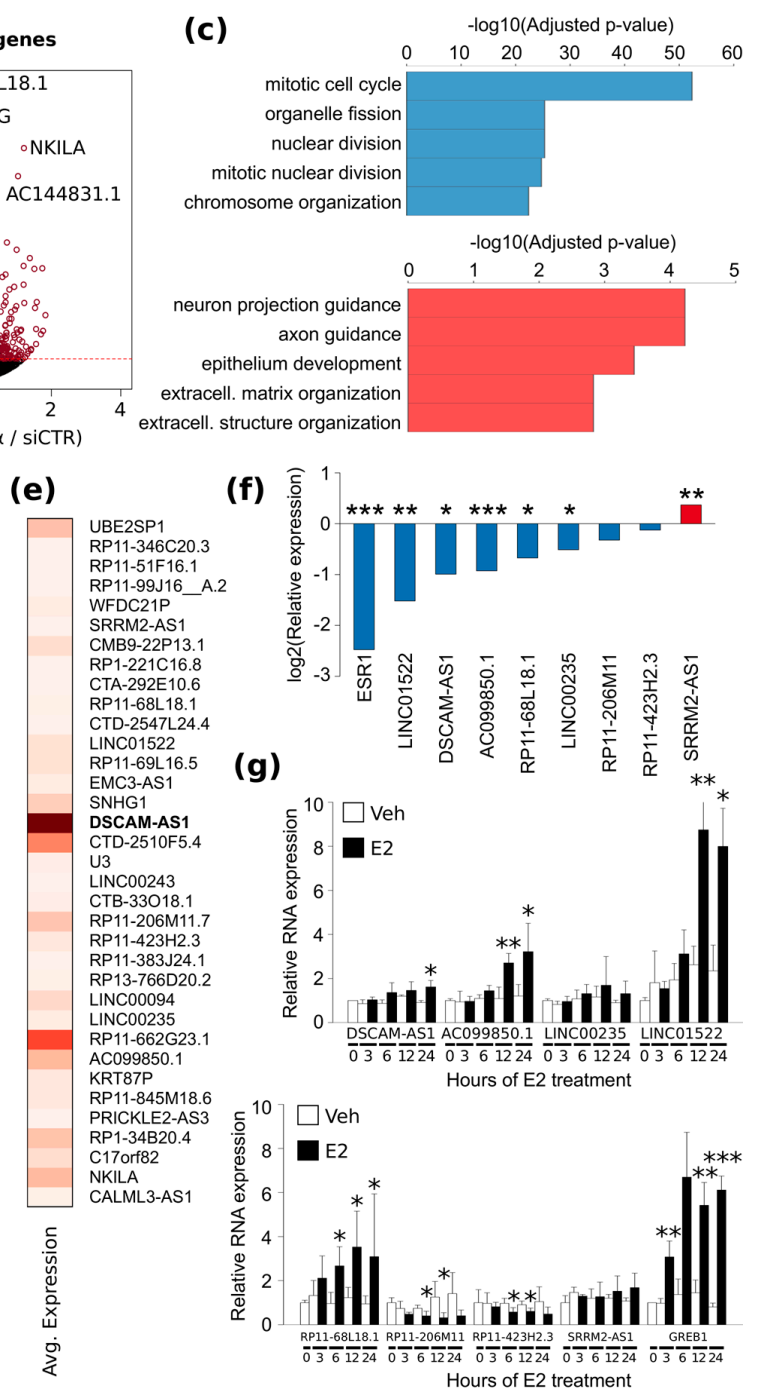

Figure 1. ApoER $\alpha$ regulated genes through SE binding. (a,b) Volcano plots reporting the adjusted $p$-value and the log2 Fold Change (FC) of (a) the protein-coding genes and (b) lncRNAs computed from RNA-seq data comparing MCF-7 cells transfected with siER $\alpha$ and siCTR in hormone-deprived (HD) medium; (c) Bar plot reporting the - $\log 10$ adjusted $p$-value of the most significant Gene Ontology Biological Processes enriched for the genes down-regulated (top) or up-regulated (down) upon ER $\alpha$ silencing in HD; (d) Heat map illustrating differential expression of Super-Enhancer (SE)-associated lncRNAs upon siER $\alpha$ transfection and upon nine-hours E2 treatment; (e) Heat map illustrating expression values of SE-associated lncRNAs as FPKM; (f) Bar plot reporting the log2 relative expression of ER $\alpha$ mRNA and eight candidate SE-associated lncRNAs upon ER $\alpha$ silencing in HD; $p$-value of three biological replicates by unpaired t-test: ${ }^{*} p<0.05$; ${ }^{* *} p<0.01$; ${ }^{* * *} p<0.001$; (g) Bar plot reporting the relative expression of eight candidate SE-associated lncRNAs and GREB1 (positive control) in a time-course experiment of $17 \beta$-estradiol (E2) or vehicle (Veh) treatment; SD of three biological replicates; $p$-value by unpaired t-test: ${ }^{*} p<0.05 ;{ }^{* *} p<0.01$; ${ }^{* * *} p<0.001$.

To understand whether SE-associated lncRNAs may represent a subset of the estrogen-responsive noncoding genes, we considered RNA-seq data from a time-course E2 experiment that is, an RNA-Seq experiment performed on MCF-7 cells collected after vehicle or E2 treatment (nine experimental time points: from 5 to $1280 \mathrm{~min}$ ) (Supplementary Table S5; GSE62789) [25]. The heat map shown in Figure $1 \mathrm{~d}$ represents the $\operatorname{lncRNA} \log 2 \mathrm{FC}$ differential expression upon apoER $\alpha$ silencing or during E2 treatment. This analysis uncovered 21 E2-responsive lncRNAs associated with an SE-aERBS. 
Specifically, eight lncRNAs down-regulated by E2 treatment were up-regulated by apoER $\alpha$ silencing; conversely, only three lncRNAs were up-regulated by E2 and down-regulated by siER $\alpha$. Interestingly, the majority of lncRNA down-regulated by siER $\alpha$ were not significantly modulated by E2 treatment. Since the genes expressed at lower levels are biased toward high absolute log2FC, we verified the expression level of these lncRNAs in terms of Fragments Per Kilobase per Million (FPKM). As shown in Figure 1e, DSCAM-AS1 was the lncRNA with the highest level of expression among our set of apoER $\alpha$-regulated lncRNAs and its expression was not significantly affected by the E2 treatment as previously reported [21]. Among the lncRNA associated to a SE-aERBSs, we verified experimentally eight lncRNAs for their responsiveness to siER $\alpha$ or E2 treatment. As reported in Figure 1f, five out of eight lncRNAs showed a significant reduction of expression level in siER $\alpha$-treated cells, while the lncRNA SRRM2-AS1 was significantly up-regulated. In E2-treated cells three lncRNAs were up-regulated while two tested lncRNAs were down-regulated. DSCAM-AS1 was only slightly significant up-regulated after $24 \mathrm{~h}$ of E2 treatment (Figure 1g).

\subsection{DSCAM-AS1 SE Characterization in Hormone-Deprived MCF-7}

We focused our analysis on DSCAM-AS1 in consideration of its unexpected abundance and unresponsiveness to $\mathrm{E} 2$, which suggest a peculiar hormone-independent transcriptional regulation involving SE regions.

In the SE mapped upstream of the DSCAM-AS1 locus, we observed nine different SE-aERBSs (named E1-9). To identify which of these regions is involved in DSCAM-AS1 regulation, we used public ER $\alpha$ Chromatin Interaction Analysis with Paired-End-Tag sequencing (ChIA-PET) data of MCF-7 grown in full medium condition (GSE39495) [26]. We observed that DSCAM-AS1 promoter interacts directly with two SE-aERBSs, E6 and E8, in particular E6 was characterized by the higher number of interactions (Supplementary Figure S1c). Overlap with aERBSs epigenetic classification performed in [27] confirmed that these regions are classified as active and transcribed enhancer (EnhT). Known long-range interactions were also confirmed using the TFF1 gene as positive control for the analysis.

Then, to explore the genomic and epigenomic context of the nine SE-aERBSs of the DSCAM-AS1 locus, we took advantage of public MCF-7 ChIP-Seq data obtained in HD condition. Using the WashU genome browser, we integrated these data with the RNA-seq and ChIP-seq experiments of HD MCF-7 transfected with siER $\alpha$ or control siRNA (Figure 2a). As expected, the nine SE-aERBSs were characterized by an enhancer histone epigenetic pattern, with high DNaseI hypersensitivity, enhancer RNA transcription measured by Global Run-On and sequencing (GRO-Seq) [28], and H3K27ac and H3K4me1 enrichment. Conversely, the histone modifications at DSCAM-AS1 TSS show typical promoter features, as H3K4me3 enrichment and high-level of RNA polymerase II (RNAPII) occupancy. In addition, the SE-aERBSs (particularly E5 and E6) were characterized by the enrichment of Forkhead Box A1 (FoxA1), Forkhead box protein M1 (FoxM1), histone acetyltransferase p300 and GATA Binding Protein 3 (GATA3), confirming the active status of these regulatory regions. Interestingly, the RNAPII ChIP-Seq signal at the DSCAM-AS1 locus decreases rapidly in the region downstream DSCAM- $A S 1$, where a CTCF binding sites is characterized by a ChIP-Seq enrichment of components of the cohesin complex RAD21 and STAG1 (GSE25021) [29]. To further confirm the candidate long-range chromatin interactions involving DSCAM-AS1 locus and the SE-aERBSs, ER $\alpha$ and CTCF ChIA-PET data were visualized. This data confirms a consistent interaction between the DSCAM-AS1 promoter and E5, E6, and E8 SE-aERBSs. 


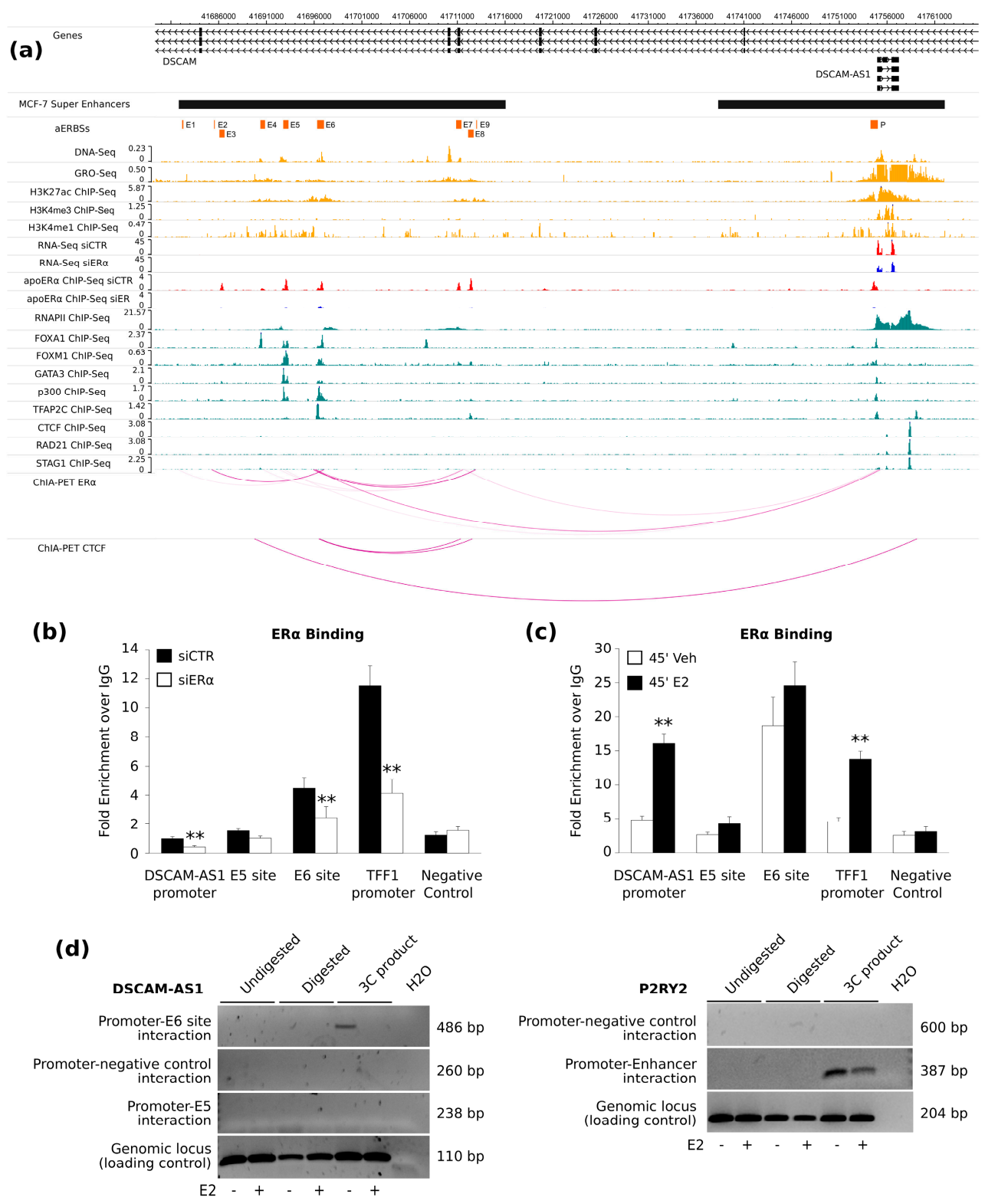

Figure 2. Characterization of DSCAM-AS1 SE in MCF-7 cells. (a) WashU genome browser view of the $D S C A M-A S 1$ genomic locus, which is reported in association with apoER $\alpha$ ChIP-Seq and RNA-Seq reads enrichment in siCTR-(red) or siER $\alpha$-(blue) transfected MCF-7 cells; and with GRO-Seq, ChIP-Seq profiles of histone modifications and DNase hypersensitivity signals (yellow), RNA-Pol II and eight TFs (teal-blue) obtained from vehicle treated MCF-7 cells (see the Materials and Methods section for detailed data source). ER $\alpha$ and CTCF ChIA-PET data performed in MCF-7 grown in full medium from ENCODE project are also included [26]. The coordinates of the predicted SE and aERBSs are reported at the top as black and orange boxes, respectively. ChIP-Seq genomic signal profiles are reported as read count per million sequenced reads. $(\mathbf{b}, \mathbf{c})$ Bar plots reporting ER $\alpha$ fold enrichment over IgG signal by ChIP-qPCR at DSCAM-AS1 promoter and E5-E6-enhancers, TFF1 promoter (positive control) and KCNQ1OT1 promoter (negative control), in MCF-7 cells grown in HD medium transfected with siER $\alpha$ or siCTR (b); treated for $45^{\prime}$ with $17 \beta$-estradiol (E2) or vehicle (veh) (c). Standard error of four biological replicates; $p$-value by unpaired $t$-test: ${ }^{* *} p<0.01$; (d) Left. Qualitative PCR reactions with primers detecting DSCAM-AS1 promoter interaction with E5 or E6 enhancer sites; primers detecting DSCAM-AS1 genomic region or non-interacting region; Right. Qualitative PCR reactions with primers detecting $P 2 R Y 2$ promoter-enhancer interaction; primers detecting $P 2 R Y 2$ genomic region or non-interacting region. All reactions were loaded on $2 \%$ agarose gel. Undigested and Digested samples represent DNA controls recovered during $3 \mathrm{C}$ libraries production. 
To investigate the role of apoER $\alpha$ in the regulation of DSCAM-AS1 expression, we focused our analysis on E5 and E6 SE-aERBSs characterized by the highest apoER $\alpha$ signal and co-factor co-occupancy. By ChIP-qPCR we first evaluated ER $\alpha$ enrichment in MCF-7 cells maintained in HD medium and transfected with siER $\alpha$ or control siRNA. Knockdown of ER $\alpha$ was monitored by western blot, observing a reduced level of the protein (73.5\%, Supplementary Figure S1d,e). The apoER $\alpha$ binding in E5, E6 and DSCAM-AS1 promoter aERBSs was confirmed by ChIP-qPCR and it decreased significantly upon ER $\alpha$ silencing (Figure 2b), indicating that these are bona fide aERBS in the absence of hormones. The TFF1 and $K C N Q 1 O T 1$ promoters were used as ER $\alpha$-binding positive and negative controls, respectively. We also observed a decreasing trend of ER $\alpha$ binding at promoter and SE-aERBSs of three lncRNAs and a significant reduction of ER $\alpha$ binding at AC099850.1 and LINC00243 SEs upon ER $\alpha$ silencing (Supplementary Figure S1f), suggesting a general ER $\alpha$-SE controlled regulation of lncRNAs expression in absence of estrogens.

Next, we wanted to ascertain if SE-aERBSs of DSCAM-AS1 were also estrogen-responsive. Thus, we evaluated ER $\alpha$ enrichment in MCF-7 cells grown in HD medium for four days and then treated with $17 \beta$-estradiol (E2) or vehicle for $45 \mathrm{~min}$, by ChIP-qPCR. We observed a significant enrichment of ER $\alpha$ binding upon E2 treatment at the TFF1 gene promoter used as a positive control, as well as on the DSCAM-AS1 promoter [21] (Figure 2c). Interestingly, we noticed no significant enrichment of ER $\alpha$ signal upon E2 treatment at E5 and E6 SE-aERBSs regions suggesting an estrogen-independent $\mathrm{ER} \alpha$ action on this region.

To verify the physical interaction between DSCAM-AS1 promoter and SE, we performed a Chromosome Conformation Capture (3C) analysis. Interestingly, we detected E6-promoter interaction in vehicle-treated cells, whereas no interactions between the E5 site and DSCAM-AS1 promoter were observed (Figure 2d). As a positive control, $P 2 R Y 2$ promoter-enhancer interaction was confirmed. No signal was observed in either DSCAM-AS1 or P2RY2-negative controls. This result gave us a first evidence of the direct interaction between ER $\alpha$-bound enhancer and DSCAM-AS1 promoter in absence of hormones.

To investigate if ER $\alpha$ knockdown also influences co-factors binding at the DSCAM-AS1 enhancer region, we performed a ChIP-qPCR analysis against p300, Gata3 and FoxM1 proteins on MCF-7 cells maintained in HD and transfected with control or siER $\alpha$. ER $\alpha$ silencing induced a significant decrement of GATA3 binding at both DSCAM-AS1 promoter and E6-enhancer regions, while p300 binding was significantly downregulated only at E6 SE-aERBS (Figure 3a,b), suggesting that the activity of this SE critically depends on the presence of ER $\alpha$. Since p300 and GATA3 protein levels did not change upon $\mathrm{ER} \alpha$ silencing (Supplementary Figure S1d,e), we concluded that the observed reduced binding of these co-factors depends rather on the presence of ER $\alpha$ in the region than on a transcriptional regulation. On the contrary, FoxM1 binding was not significantly affected by ER $\alpha$ silencing.
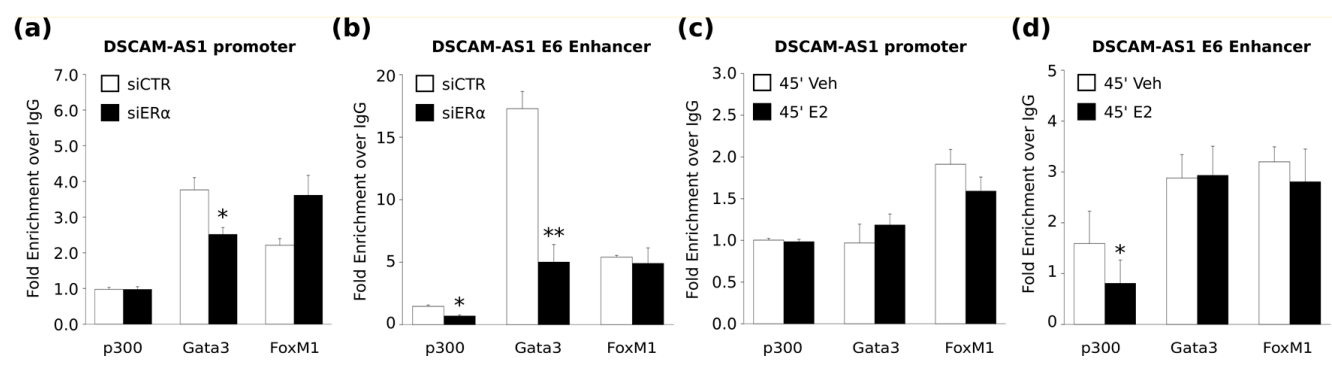

Figure 3. Analysis of ER $\alpha$ co-factor binding at DSCAM-AS1 locus. (a,b) Bar plots reporting p300, GATA3 and FoxM1 fold enrichment over IgG signal at DSCAM-AS1 promoter (a) and E6-enhancer (b) by ChIP-qPCR in MCF-7 cells grown in HD and transfected with siCTR or siER $\alpha$; (c,d) Bar plots reporting p300, GATA3 and FoxM1 fold enrichment over IgG signal at DSCAM-AS1 promoter (c) and E6-enhancer (d) by ChIP-qPCR in MCF-7 cells grown in HD and treated for $45^{\prime}$ with $17 \beta$-estradiol (E2) or vehicle (veh). Standard error of three biological replicates; $p$-value by unpaired $t$-test: ${ }^{*} p<0.05$; ** $p<0.01$. 
Interestingly, we observed significant decrease of p300 occupancy within DSCAM-AS1 SE-aERBS upon E2 treatment (Figure 3c,d), suggesting a hormone-independent activation of DSCAM-AS1 SE. By contrast, p300 binding on DSCAM-AS1 promoter region showed no change upon E2 treatment.

Since CTCF binding sites were mapped downstream the DSCAM-AS1 gene and a long-range interaction between this site and a site farther upstream to the SE was identified by ChIA-PET (Figure 2a), we asked whether CTCF binding could be involved in the DSCAM-AS1 enhancer-promoter regulatory interactions. We studied CTCF binding downstream the DSCAM-AS1 region and upstream the associated SE by ChIP-qPCR. Noteworthy, CTCF binding dropped significantly upon ER $\alpha$-silencing in the upstream region of DSCAM-AS1 SE (Supplementary Figure S1g), without any change of the CTCF protein level (Supplementary Figure S1d,e), strengthening again the central role of ER $\alpha$ in the maintenance of an active SE. Interestingly, we found that CTCF occupancy tends to decrease upstream the DSCAM-AS1 SE and significantly diminishes downstream the DSCAM-AS1 gene after E2 treatment, suggesting an hormone-independent CTCF insulation of DSCAM- $A S 1$ enhancer-promoter interaction.

\subsection{DSCAM-AS1 SE Characterization in Drug-Resistant BC Cell Lines}

Since chromatin binding of luminal BC-specific TFs (ER $\alpha$, Gata3, FoxM1) is enriched at $D S C A M-A S 1-S E$, we verified whether the same genomic regions were predicted as an active SE in other BC cell lines. For this analysis, we used H3K27ac ChIP-Seq data from [30] in which the authors created different somatic cell fusions between luminal and basal BC cell lines. As reported in Supplementary Figure S2a the analysis of SEs in these cell lines revealed that DSCAM-AS1 SE was predicted only in luminal MCF-7 and T-47D cell lines but not in any of the basal or basal/luminal fusion cell lines. The H3K27ac signal at SE is lower in T-47D cells, as compared to MCF-7, and almost absent in ZR-75.1 cells; surprisingly, we observed that DSCAM-AS1 expression is up-regulated by E2 in these cell lines (Supplementary Figure S2b,c).

To further explore the relationship between DSCAM-AS1 expression and the activity of the associated SE, we analyzed public ER $\alpha$ and H3K27ac ChIP-Seq data obtained in Long-Term Estrogen Deprived (LTED) models and Tamoxifen resistant model from [31]. As reported in Figure 4a, ER $\alpha$ binding at DSCAM-AS1 SE occurs as well in wild-type as in Tamoxifen resistant and in LTED models. Only in a LTED model, which is resistant also to Tamoxifen, is the binding absent, despite the high H3K27ac ChIP-Seq signal still measured in this region. Noteworthy, the highest ER $\alpha$ ChIP-Seq signal at E6 SE-aERBS was observed in the LTED model.

Analysis of ER $\alpha$ and H3K4me3 ChIP-Seq data of primary tumor tissues from patients who respond or not to AI treatment [32] showed an higher H3K4me3 signal in AI-resistant than in AI-responder patients (Figure $4 \mathrm{~b}$ ); in particular, in four out of six cases of AI-resistant patients a clear H3K4me3 signal at DSCAM-AS1 promoter and gene locus combines with a low but evident ER $\alpha$ ChIP-Seq signal at both E6 and DSCAM-AS1 promoter (Figure 4b and Figure S2d).

Analysis of ER $\alpha$ and H3K4me3 ChIP-Seq data of primary tumor tissues from patients responding or not to AI treatment [32] showed higher H3K4me3 signal in AI-resistant than in AI-responder patients (Figure $4 \mathrm{~b}$ ); in particular, in four out of six cases of AI-resistant patients a clear H3K4me3 signal at DSCAM-AS1 promoter and gene locus combines with a low but evident ER $\alpha$ ChIP-Seq signal at both E6 and DSCAM-AS1 promoter (Supplementary Figure S2d). 
(a)

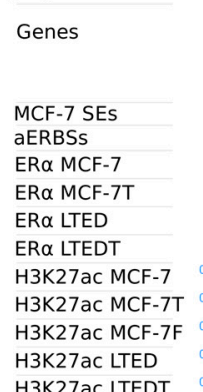

H3K27ac LTEDT

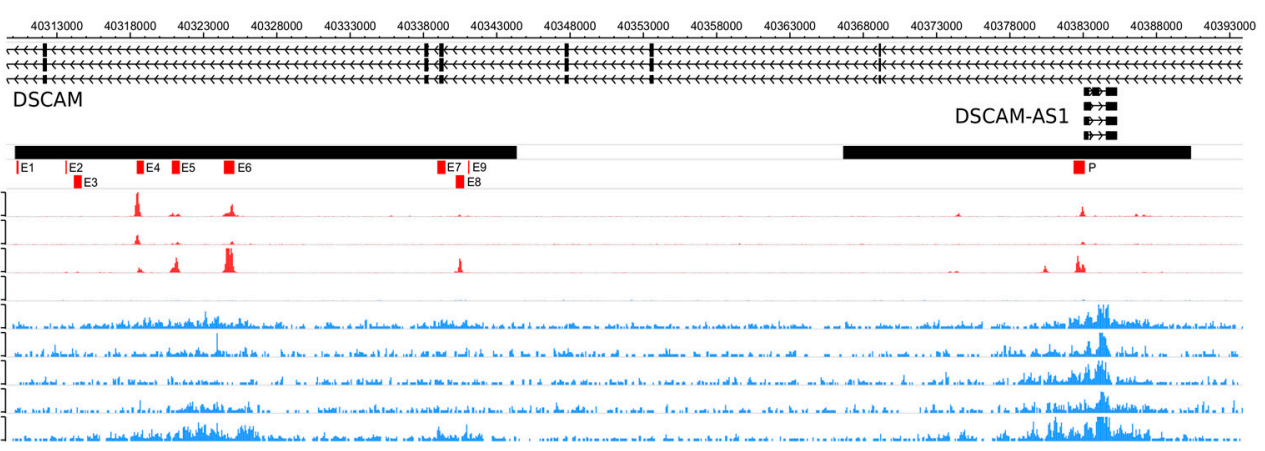

(b)
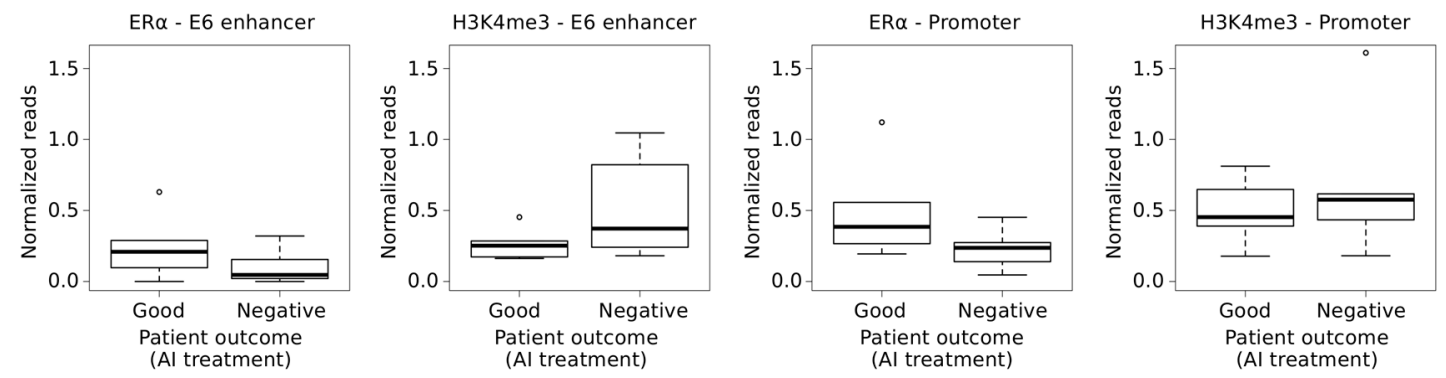

Figure 4. DSCAM-AS1 SE characterization in drug-resistant BC cell lines. (a) WashU genome browser view of DSCAM-AS1 genomic locus reporting at top the ChIP-Seq genomic signal profile of ER $\alpha$ and H3K27ac ChIP-Seq experiments performed in wild type MCF-7, MCF-7 resistant to Tamoxifen (MCF-7T), MCF-7 resistant to Fulvestrant (MCF-7F), Long Term Estrogen Deprived (LTED) MCF-7 cells, and LTED MCF-7 resistant to Tamoxifen (LTEDT) [31]. (b) Box plot reporting the normalized number of ER $\alpha$ and H3K4me3 ChIP-Seq reads counted at DSCAM-AS1 E6 enhancer (left) and promoter (right) considering data from patient responsive (Good prognosis, Good) or not (Negative prognosis, Negative) to Aromatase Inhibitors treatment (AI) [32]. Black dots represent outliers.

\section{Discussion}

In this work, we have presented novel results that help understanding the role of Estrogen Receptor $\alpha$ in absence of hormones $(a p o E R \alpha)$, which is a critical issue for Breast Cancer (BC) patients given adjuvant treatment with Aromatase Inhibitors (AIs). We performed a deep triplicate RNA-Seq in hormone-depleted MCF-7 cells upon ER $\alpha$ silencing and, specifically, we were interested to understand whether Super Enhancers (SEs) were involved in sustaining the basal expression of a group of luminal-specific lncRNAs. Our study indicates that a set of apoER $\alpha$ dependent lncRNAs lie close to SEs, suggesting a strict dependence on these regions. Focusing on a representative IncRNA gene, DSCAM-AS1, we observed that aERBSs within the major SE in this region are active enhancers, also displaying long-distance contacts with the DSCAM-AS1 promoter, even in the absence of hormones. Moreover, our data suggests that the chromatin domain confining this interaction may depend upon the estrogen-independent CTCF binding in proximity of DSCAM-AS1. Finally, comparison of $\mathrm{SE}$ activity in different $\mathrm{BC}$ cell lines revealed a relationship between ER $\alpha$ expression level and SE activity as well as DSCAM-AS1 responsiveness to E2 treatment. Noteworthy, we confirmed the active epigenetic status of DSCAM-AS1 locus in BC patients unresponsive to AI, but low ER $\alpha$ binding at $\mathrm{SE}$ was observed in these samples.

The identification of SEs helped us to understand the peculiar transcriptional program regulating cell-type specific gene expression. Recently, several evidences demonstrated that cell-specific enhancers play an important role in tumorigenesis [11]. Indeed, the study of SEs driving the expression of specific cancer associated lncRNAs may delineate an additional informative layer on cancer development. 
One important limitation of our results is represented by the fact that the possible targets of SE were identified only based on the distance, i.e., we attributed to each SE the closest apoER $\alpha$-regulated IncRNA gene. While on the basis of the reported frequency of enhancer-promoter interaction this is justified, the ENCODE project and other studies have reported that in a number of cases enhancers interact with promoters jumping over several genes [26]. Clearly, the matter would require direct long-range interaction studies using the Hi-C technology [33] and derivatives. Nevertheless, at least in the case of DSCAM-AS1, the prediction appeared correct and could be confirmed by our ChIA-PET network model.

The expression of the carcinoma-specific DSCAM-AS1 is particularly interesting due to its abundance and close association with unliganded ER $\alpha$ activity. DSCAM-AS1 loss impairs indeed BC cells proliferation and its expression is somehow implicated in Tamoxifen-resistance [21,22]. Here, we confirmed and extended previous results of our group [21] by validating ER $\alpha$ binding both in the promoter region and in putative enhancer elements that was very high in absence of estrogen, demonstrating only a slight increase after estradiol stimulation, and confirmed that this increase is not paralleled by transcriptional activation, whereas down-regulation of ER $\alpha$ by RNA interference led to significant transcriptional inhibition. On the contrary, low levels of the coding DSCAM transcript are detectable in breast cancer cells and no function of DSCAM in mammary tissues has been described to date. DSCAM mRNA slightly decreases upon ER $\alpha$-silencing but it appears induced by estrogen [21,34], suggesting that the estrogen-induced re-localization of aERBSs might differentially regulate the expression of these sense and antisense transcripts in BC cells. Altogether, this data indicates a specific ligand-independent ER $\alpha$ program to sustain DSCAM-AS1 expression in BC cells.

The presence of apoER $\alpha$ bound to an intronic element, which can increase quantitatively in response to estrogen but not transcriptionally, is not novel: a similar situation was reported for an intronic site in the retinoic acid receptor alpha 1 gene $(R A R A)$ [35] suggesting that such regulatory modality may be more frequent in IncRNA genes, but also present in protein-coding genes. Notably, also the RARA gene has a very important developmental function in epithelial mammary cells. One important novel finding in our data is represented by the state of activation of the aERBS within the major SE upstream the DSCAM-AS1 gene. We evaluated p300 enrichment confirming the active status of these regulatory regions. In particular, the transcriptional coactivator p300 possesses intrinsic acetyltransferase activity and it was shown to play a critical role in transcriptional regulation [36]. Consistent with our results, p300 occupancy is a highly accurate method to identify enhancers and their associated activities $[37,38]$. Interestingly, we observed that ER $\alpha$ depletion induced a decrease of p300 occupancy, suggesting that the activity of these enhancers requires the presence of ER $\alpha$. Moreover, p300 binding to the DSCAM-AS1 enhancer is conserved rather in hormone-deprived medium than upon estrogen treatment, indicating that this $\mathrm{SE}$ is not an early estrogen target site. However, the dynamic distribution of p300 in BC cells in the presence or absence of estrogenic hormones and its effect on the prognosis of BC are poorly understood [38].

Our analysis confirms the model where apoER $\alpha$ collaborates with other TFs to maintain the luminal epithelial enhancer landscape [6]. These cooperation are underlined by the cross-regulatory loop involving GATA-3 and ER $\alpha$ or AP2 $\gamma$ and ER $\alpha$, which sustain each other's expression in BC cells $[39,40]$. Interestingly, we also observed that ER $\alpha$ depletion induced a decrease of GATA3 occupancy; therefore, the regulation of DSCAM- $A S 1$ gene expression seems to be based on long range interaction between apoER $\alpha$-bound enhancer and the gene promoter as previously described for some estrogen-dependent ER $\alpha$ target genes such as TFF1 and GREB1 [41]. Noteworthy, our analysis suggests that only the E6 aERBS is involved in DSCAM-AS1 regulation. In fact, both ER $\alpha$ binding and $3 C$ analysis show very low activity of E5, also reflecting public ChIA-PET data of MCF-7 cells grown in full medium, i.e., under low hormone concentrations [26].

Therefore, we attempted DSCAM- $A S 1$ promoter-enhancer interaction before and after estrogen stimulation and we could detect at least the E6-promoter interaction, further demonstrating that this 
enhancer is active even in the absence of estrogen. However, it should be emphasized that this is a preliminary and qualitative result, which should be confirmed by further experiments to quantify the frequency of $D S C A M-A S 1$ promoter-enhancer interaction in different experimental conditions. This data will allow understanding if this interaction is more favored or stabilized in absence of hormones, as we hypothesize.

The eukaryotic genome is organized into functionally and structurally distinct chromatin domains which orchestrate spatial and temporal gene regulation. CTCF, the most characterized insulator-binding protein, is directly involved in chromatin architecture by the formation of barriers which limit the diffusion of chromatin states and promote tissue-specific local chromatin hubs. CTCF binding to insulator sequences can partition the genome into distinct ER $\alpha$-regulatory blocks [42] defining sensitive and insensitive regions [43]. However, redistribution of CTCF binding sites after E2 treatment was not generally observed [44]. Since CTCF binding sites were mapped around $D S C A M-A S 1$ and a long-range interaction was observed between a site close to DSCAM-AS1 3' end and a site farther upstream the SE, we asked whether CTCF binding could justify the peculiar mode of action of the DSCAM-AS1 enhancer/promoter regulatory system. Noteworthy, we found that CTCF occupancy upstream DSCAM-AS1 decreases after ER $\alpha$ silencing in HD medium, whereas it decreases significantly downstream the DSCAM- $A S 1$ gene region after estradiol stimulation, suggesting that estrogen, or its absence, may induce a redistribution of long-range interactions. Taken together, these results suggest a non-trivial regulatory model at this site, which may involve channeling SE action on the DSCAM-AS1 promoter in cancer cells overexpressing ER $\alpha$ due to strict domain definition by CTCF. We also supposed that the reduction of CTCF signal upon estradiol stimulation indicate that these enhancers might regulate distal genes surmounting the protein insulator. Interestingly, the analysis of public RNA-Seq data MCF-7 transfected with siCTCF and treated with E2 for $3 \mathrm{~h}$ show a reduction of DSCAM-AS1 level in siCTCF-treated cells (Supplementary Figure S2e).

Our data suggest a model in which CTCF protein acts by insulating the interaction between DSCAM-AS1 and associated SE. Within the SE a hierarchical ER $\alpha$ binding starting from E6 aERBS maintains the long-range chromatin contact even in hormone-deprived cells. A similar hierarchical model was recently proposed by different groups [14,45], however, if this model can apply to the regulation of other ER $\alpha$-dependent lncRNAs is not known at present and will require extension of these studies in the near future.

Finally, analysis of the DSCAM-AS1 locus in several BC cell lines suggested a direct correlation between the level of ER $\alpha$ expression and the DSCAM-AS1 SE activation status. Indeed, in MCF-7, (the BC cell line characterized by the highest ER $\alpha$ expression), the DSCAM-AS1 SE is completely active, while only the DSCAM-AS1 promoter region is active in ZR-75.1 (characterized by a lower ER $\alpha$ expression). Furthermore, the LTED cell model system, which is characterized by an elevated ER $\alpha$ expression [46], were also characterized by the highest ER $\alpha$ SE occupancy among all the cell lines analyzed. However, given the extensive genetic and epigenetic heterogeneity driving the acquisition of a hormone-independent phenotype in the different LTED models [31], limited general conclusion can be translated to the clinical settings.

Analysis of ER $\alpha$ and H3K4me3 ChIP-Seq data clearly show extensive heterogeneity among patients. Using these data, we were not able to confirm a strong ER $\alpha$ binding at DSCAM-AS1 SE, but we clearly observed that DSCAM-AS1 locus is active in four out six patients non-responsive to AI treatments. Since patients with a good prognosis present no H3K4me3 signal at DSCAM-AS-SE, its activated-status is correlated with a negative prognosis, suggesting it as epigenetic-predictor of AI-treatment response. As far as the other common endocrine treatment is concerned, i.e., Tamoxifen, Niknafs and coworkers reported that Tamoxifen-resistant patients display ER $\alpha$ binding to DSCAM-AS1 promoter, as opposed to Tamoxifen responders [22]. Using the same data [47], we additionally examined ER $\alpha$ binding at the DSCAM-AS1 SE, confirming that ER $\alpha$ binding is limited to non-responder patients (Supplementary Figure S2d,f). Altogether, these data support the fact that DSCAM-AS1 does 
not behave as a typical estrogen-responsive gene, since its active transcriptional status is maintained both in absence of estrogen (AI) and in the presence of antagonistic ER $\alpha$ ligands (Tamoxifen).

Moreover, DSCAM-AS1 genes was included in the gene classifier of drug responsiveness proposed by Jansen and colleagues [32].

In our lab, we are actively exploring DSCAM-AS1 expression in tissues of $\mathrm{BC}$ patients to demonstrate it possible role as hormone-responsiveness marker. At the same time, several other lncRNA loci are being studied to understand unliganded ER $\alpha$ action in luminal breast cancer.

\section{Materials and Methods}

\subsection{Cells Culture and Treatment}

MCF-7 and ZR-75.1 cells were routinely grown in DMEM medium supplemented with $10 \%$ heat-inactivated FBS, $2 \mathrm{mM}$ L-glutamine, $50 \mathrm{U} / \mathrm{mL}$ penicillin and $50 \mu \mathrm{g} / \mathrm{mL}$ streptomycin. T-47D cells were routinely grown in RPMI medium supplemented with $10 \%$ heat-inactivated FBS, $2 \mathrm{mM}$ L-glutamine, $50 \mathrm{U} / \mathrm{mL}$ penicillin and $50 \mu \mathrm{g} / \mathrm{mL}$ streptomycin. Hormone-deprived medium (HD) was obtained from phenol red-free DMEM supplemented with 5\% charcoal-dextran-treated serum. MCF-7 cells were grown at least 4 days in HD medium before $17 \beta$-estradiol treatment (E2). 17 $\beta$-estradiol (Sigma -Aldrich, St. Louis, MO, USA) was added at a final concentration of 10-8 M.

\subsection{Small Interfering RNA (siRNA)}

MCF-7 cells were grown in HD medium (for two days in this conditioned medium) before being transfected with siRNAs using Lipofectamine2000 (Life Technologies, Carlsbad, CA, USA), according to the reverse transfection protocol. Stealth $\mathrm{RNAi}^{\mathrm{TM}}$ siRNAs from Invitrogen were used to target ER $\alpha$ mRNA (ESR1HSS103376, ESR1HSS103377, ESR1HSS176619); stealth RNAi ${ }^{\mathrm{TM}}$ siRNA Negative Control medium GC was used as a control (siCTR). Any experiment was carried out $48 \mathrm{~h}$ after siRNA transfection in order to achieve the maximum efficiency of RNA interference.

\subsection{RNA-Seq}

MCF-7 cells were grown for 2 days in HD medium before siRNAs transfection (siCTR or siERa). RNA was harvested after $48 \mathrm{~h}$ from transfection by RNA isolation kit (RNeasy Mini Kit, Qiagen 74104). RNA quality check (RNA integrity number (RIN) > 8) was achieved with Fragment Analyzer (Advanced Analytical Technologies, Inc, Ankeny, IA, USA) and quantified with Qubit (Qubit ${ }^{\mathrm{TM}}$ RNA HS Assay Kit, ThermoFisher Scientific, Waltham, MA, USA;Q32852). Two $\mu \mathrm{g}$ of RNA were polyA+ selected and RNA-Seq libraries were constructed using Illumina TruSeq RNA sample prep kit (TruSeq ${ }^{\text {TM }}$ RNA Sample Prep Kit v2-Set B, Illumina, RS-122-2002). Paired-end (PE) cluster generation was performed using cBot on Flow Cell v3 (TruSeq PE Cluster Kit v3-cBot-HS, Illumina, PE-401-3001). Sequencing of libraries was performed on the HiSeq sequencing system (Illumina, San Diego, CA, USA).

Raw and processed RNA-Seq data were deposited at GSE108693.

\subsection{RNA-Seq Data Analysis}

Raw RNA-Seq reads were aligned using TopHat v2 [48]. Gencode v24 was used as reference set of gene annotations. Read count was performed using featureCounts algorithm [49] and read count tables were normalized with DESeq2 package [50]. Normalized read counts were converted to fragments per kilobase of exons per million fragments mapped (FPKM) considering the length of the longest isoform of each gene and the millions of reads counted by featureCounts.

Differentially expression between siCTR and siER $\alpha$-treated MCF-7 was performed using DESeq 2 in default settings. A gene was considered as differentially expressed if associated with an adjusted $p$-value $<0.001$. To identify genes differentially expressed in the time-course E2-treatment experiment, maSigPro R package [51] was applied in default setting by considering the adjusted $p$-value computed 
using the p.vector function of the package. A gene was considered as differentially expressed if associated with an adjusted $p$-value $<0.05$. Gene to SEs association was performed by computing the distance between gene TSSs and each SE center. Only genes mapped within $100 \mathrm{kbp}$ from a SE region were considered for the analysis.

Gene set functional analysis was performed using Enrichr algorithm [52].

Analysis of GRO-Seq datasets from GSE45822 was performed using Bowtie v2.1.0 [53] in default settings and the local option.

\subsection{Super Enhancer Prediction}

A H3K27ac ChIP-Seq dataset performed on 48-h hormone-deprived MCF-7 cells treated with vehicle (GSM986079) was used for the identification of SE regions. Raw ChIP-Seq reads were aligned using Bowtie 2.0 algorithm in default settings [53]. Significant H3K27ac ChIP-Seq peaks were called with MACS 2.1.0 [54]. The input ChIP-Seq experiment was used as background for the analysis (GSM986091). These peaks were used as input for the ROSE algorithm [24] analysis applied in default settings. Only SEs overlapped against apoER $\alpha$ ChIP-Seq peaks defined in [6] were selected for the analysis. The set of SEs predicted in other BC cell lines were retrieved from [30] supplemental material. These SE coordinates were converted in hg38 using LiftOver algorithm (https:/ / genome.ucsc.edu/cgibin/hgLiftOver).

\subsection{Long Range Chromatin Interaction Network}

The network model of Gene-aERBSs chromatin interaction was generated using the ChIA-PET data from GSE39495. Each pair of interacting genomic regions was overlapped with the aERBSs and gene promoter coordinates. A promoter was defined as a region of $-2 \mathrm{kbp}$ and $+500 \mathrm{bp}$ around the gene TSS. Each aERBS was equally extended by $1 \mathrm{kbp}$ in each size. The average number of interacting region between each aERBS-gene, gene-gene, or aERBS-aERBS pair was computed and represented as link width between the connected nodes. Gene were color-coded according to their expression log2FC in the siER $\alpha$ RNA-Seq experiment while aERBS nodes were colored according to their epigenetic classification defined in [27].

\subsection{DSCAM-AS1 Locus Analysis}

The analysis of DSCAM-AS1 locus and upstream enhancer regions was performed using the Washu Genome Browser [55]. ChIP-Seq genomic signals from public experiments performed in hormone-deprived MCF-7 were defined by realignment of raw ChIP-Seq reads using Bowtie 2.0 algorithm in default settings. Then, alignment bam files were converted to bedgraph files using BEDTools algorithm [56]. Each ChIP-Seq genomic signal was converted in count per millions by dividing the read coverage data by the million number of sequencing reads in each experiment. In the analysis data from a ChIP-Seq performed against H3K27ac (GSM1115993), H3K4me3 (GSM1382470), H3K4me1 (GSM1382469), RNAPII (GSM1116656), FoxA1 (GSM588929), FoxM1 (GSM1001003), Gata3 (GSM986074), p300 (ERR045733), AP2 $\gamma$ (GSM588927), CTCF (GSM822308), Rad21 (GSM614613), and Stag1 (GSM614616) were considered. ER $\alpha$ ChIP-Seq and RNA-Seq data from siCTR or siER $\alpha$-transfected MCF-7 (GSE53533) were also considered in the analysis. DNase-seq were obtained from GSM1024764. ER $\alpha$ and H3K4me3 ChIP-Seq data from AI-treated patients were obtained from GSE40867 while data from Tamoxifen-treated patients were retrieved from GSE32222.

Data from ENCODE long-range chromatin interaction experiments were analyzed by considering the ER $\alpha$ and CTCF ChIA-PET experiments performed in complete-medium grown MCF-7. The processed data of these experiments were provided by the public track hub "long-range chromatin interaction experiments" of the Washu Genome Browser. 


\subsection{Protein EXTract and Western Blot Analysis}

Whole-cell lysate was harvested from organic-phenol phase after RNA purification in Purezol ${ }^{\mathrm{TM}}$ reagent (Bio-Rad, Hercules, CA, USA). $70 \mu \mathrm{g}$ of protein extracts were denatured by boiling in 6x Loading Dye, fractionated by SDS-PAGE electrophoresis in $6 \%$ polyacrylamide gel and finally transferred on PVDF membrane (Millipore). Antibodies used were designed against ER $\alpha$ (Santa Cruz Biotechnology, Dallas, TX, USA; sc543 and sc-7207), CTCF (Merck-Millipore, Burlington, MA, USA; 07-729), GATA3 (Santa Cruz Biotechnology, Dallas, TX, USA; sc-268), p300 (Santa Cruz Biotechnology Dallas, TX, USA sc-585), FOXM1 (Santa Cruz Biotechnology Dallas, TX, USA sc-376471) and Hsp90 (Cell Signaling Technology, Danvers, MA, USA; 4874) proteins. Proteins quantitation was performed with Volume Analysis Tool from Quantity One ${ }^{\mathrm{TM}}$ software, version 4.6.6 (Bio-Rad).

\subsection{RNA Isolation and Quantitative Real-Time PCR ( $q R T-P C R$ )}

RNA was isolated from MCF-7 cells using Purezol ${ }^{\mathrm{TM}}$ reagent (Bio-Rad). All total isolated RNAs were subjected to DNase treatment to remove contaminating genomic DNA (ezDNase ${ }^{\mathrm{TM}}$ Enzyme, Invitrogen, Carlsbad, CA, USA; 11766051). First strand cDNA synthesis from $250 \mathrm{ng}$ of total RNA template was performed with SensiFAST cDNA Synthesis Kit (Bioline, London, UK; BIO-65054), followed by SYBR-green qRT-PCR amplification (iTaq UniverSYBR Green, Bio-Rad 1725124). Real-time PCR primers for human 18S, ER $\alpha$, GREB1 RNAs were purchased from Qiagen (Hilden, Germany; QuantiTect ${ }^{\mathrm{TM}}$ Primer Assay). Custom expression-primer pairs are reported in Supplemental Table S6.

\subsection{Chromatin Immunoprecipitation Assay (ChIP)}

MCF-7 cells were grown for 2 days in HD medium before siRNAs transfection or 45 min of E2 treatment. ChIP experiments were then performed as follows: cells were cross-linked by addition of formaldehyde at $1 \%$ final concentration (Formaldehyde solution, Sigma-Aldrich 252549) and incubated $10 \mathrm{~min}$ at $37^{\circ} \mathrm{C}$. Cross-linking was stopped by addition of glycine solution to a final concentration of $0.125 \mathrm{M}$ for $5 \mathrm{~min}$ on a shaker at room temperature. Cross-linked cells were then washed twice with ice-cold PBS supplemented with complete protease inhibitors cocktail and collect by scraping (Protease Inhibitor Cocktail, Sigma-Aldrich P2714-1). Cell pellets were subjected to lysis on ice for $10 \mathrm{~min}$ with Lysis Buffer 1 ( $5 \mathrm{mM}$ Pipes $\mathrm{pH} 8,85 \mathrm{mM} \mathrm{KCl}, 0.5 \%$ NP40) supplemented with complete protease inhibitors cocktail. Subsequently, nuclei pellets, obtained by a $5 \mathrm{~min}$ spin cycle at $4{ }^{\circ} \mathrm{C}(4000 \mathrm{rpm})$ were exposed once again to 10 min lysis in Lysis Buffer 2 (1\% SDS, 5 mM EDTA, 50 mM Tris-HCl $\mathrm{pH}$ 8.1) supplemented with complete protease inhibitors cocktail. Total extracted chromatin was sonicated to an average size of $250-500 \mathrm{bp}$ by using an immersion sonicator device. The desired fragments size was checked on $1.2 \%$ agarose-gel and quantified by Nanodrop spectrophotometer at $280 \mathrm{~nm}$, in order to use $50 \mu \mathrm{g}$ of chromatin per IP. $10 \mu \mathrm{L}(1 \%)$ of chromatin extracts was recovered as input normalization-control for each experimental condition. Chromatin extracts were diluted with IP-buffer (1\% Triton X-100, 2 mM EDTA, 20 mM Tris-HCl of pH 8.1, $150 \mathrm{mM} \mathrm{NaCl}$, supplemented with complete protease inhibitors) and incubated overnight with the specific antibody or $\operatorname{IgG}$ at $4^{\circ} \mathrm{C}$ on a rotating platform. Protein A and G sepharose-beads (GE Healthcare Life Sciences; Little Chalfont, UK; 17-5280-01 and 17-0618-01 respectively) were pre-coated with IP buffer supplemented with 5\% BSA, in order to reduce nonspecific antibody binding. Upon $2 \mathrm{~h}$ of Protein A or G sepharose-beads incubation (depending on antibody source, i.e., rabbit or mouse respectively), samples were washed sequentially for $5 \mathrm{~min}$, on a rotating platform with $1 \mathrm{~mL}$ of three different Washing Buffer (Washing buffer 1: 0.1\% SDS, $1 \%$ Triton X-100, 2 mM EDTA, $20 \mathrm{mM}$ Tris $\mathrm{HCl}$ pH 8, $150 \mathrm{mM} \mathrm{NaCl}$; Washing buffer 2: 0.1 SDS, 1\% Triton X-100, 2 mM EDTA, $20 \mathrm{mM}$ Tris HCl pH 8, $500 \mathrm{mM} \mathrm{NaCl}$; Washing buffer 3: $0.25 \mathrm{M}$ $\mathrm{LiCl}, 1 \% \mathrm{NP} 40,1 \% \mathrm{Na}$ DOC, $1 \mathrm{mM}$ EDTA, $10 \mathrm{mM}$ Tris $\mathrm{HCl} \mathrm{pH} 8)$ and twice with TE buffer (10 mM Tris $\mathrm{HCl} \mathrm{pH} 8,1 \mathrm{mM}$ EDTA). After complexes elution at RT with elution buffer (1\% SDS, $0.1 \mathrm{M} \mathrm{NaHCO})$, DNA fragments were de-crosslinked at $65{ }^{\circ} \mathrm{C}$ overnight with $\mathrm{NaCl} 5 \mathrm{M}$ and by $1 \mathrm{~h}$ of proteinase $\mathrm{K}$ treatment. DNA purification was achieved with Phenol:Chloroform:IAA (25:24:1 UltraPure ${ }^{\mathrm{TM}}$ 
formulation, Ambion AM9730) according to the manufacturer's instructions. Quantitative Real-time PCR was carried out on ChIP-enriched DNA using SYBR Green Master Mix. ChIP enrichment was normalized on input samples ( $1 \%$ of total chromatin used per IP) and expressed as fold-enrichment of specific binding over the control nonspecific IgG binding. Antibodies against human ER $\alpha$ (Santa Cruz Biotechnology, Dallas, TX, USA; sc534X, sc7207X), p300 (Santa Cruz Biotechnology, Dallas, TX, USA; sc-585X), CTCF (Merk-Millipore, Burlington, MA, USA; 07-729), GATA3 (Santa Cruz Biotechnology, Dallas, TX, USA; sc-268X), FOXM1 (Santa Cruz Biotechnology, Dallas, TX, USA; sc-376471X) and normal rabbit IgG (Merk-Millipore, Burlington, MA, USA; 12-370) were used in this assay. Custom ChIP primer pairs are reported in Supplementary Table S6.

\subsection{Qualitative Chromosome Conformation Capture (3C-PCR)}

MCF-7 cells were grown for 2 days in HD medium before 45 min of E2 treatment. 3C procedure was performed essentially as described by [8] with some modifications: Step: Crosslinking reaction. As well as for ChIP experiments, cells were cross-linked by addition of formaldehyde (1\% final concentration) and incubated $10 \mathrm{~min}$ at $37^{\circ} \mathrm{C}$. Cross-linking was stopped by addition of glycine solution to a final concentration of $0.125 \mathrm{M}$ for $5 \mathrm{~min}$ on a shaker at room temperature. Cross-linked cells were then washed twice with ice-cold PBS supplemented with complete protease inhibitors cocktail and collect by scraping. Cell pellets were subjected to lysis on ice for $10 \mathrm{~min}$ with ChIP Lysis Buffer 1 supplemented with complete protease inhibitors cocktail. Subsequently, nuclei pellets, obtained by a 5 min spin cycle at $4{ }^{\circ} \mathrm{C}(4000 \mathrm{rpm})$ were resuspended with $100 \mu \mathrm{L}$ of $3 \mathrm{C}$ buffer $(50 \mathrm{mM}$ Tris- $\mathrm{HCl} \mathrm{pH} \mathrm{8.0;} 50 \mathrm{mM} \mathrm{NaCl} ; 10 \mathrm{mM} \mathrm{MgCl} 2 ; 1 \mathrm{mM}$ DTT). Step 2: Permeabilization and digestion. SDS (final concentration $0.2 \%$ ) was added and samples were incubated at $37^{\circ} \mathrm{C}$ for $1 \mathrm{~h}$ while shaking at $300 \mathrm{rpm}$. Then, Triton X-100, diluted in 1 X ligase buffer (NEB, B0202S), was added at $1.2 \%$ final concentration and samples were incubated at $37^{\circ} \mathrm{C}$ for $1 \mathrm{~h}$ while shaking at $300 \mathrm{rpm}$. A $10 \mu \mathrm{L}$ aliquot was taken by pipetting on the wall of the tube (without mixing before). This sample corresponds to undigested DNA. DNA digestion will be done by adding a total of $450 \mathrm{U}$ of restriction enzyme (BglII and NsiI, NEB R0144L and R0127L respectively) overnight at $37^{\circ} \mathrm{C}$ while shaking at $300 \mathrm{rpm}$. A $4.5 \mu \mathrm{L}$ aliquot was taken by pipetting on the wall of the tube (without mixing before). This sample corresponds to digest DNA. Step 3: Restriction enzyme inactivation and ligation of chimerical products. SDS (final concentration $0.2 \%$ ) was added and samples were incubated at $37^{\circ} \mathrm{C}$ for 30 min while shaking at $300 \mathrm{rpm}$. Samples were then diluted 4 times in 1X ligase buffer and Triton X-100, diluted in $1 \mathrm{X}$ ligase buffer, was added at $1 \%$ final concentration. Finally, samples were incubated at $37^{\circ} \mathrm{C}$ for $2 \mathrm{~h}$ while shaking at $200 \mathrm{rpm}$. After a centrifugation of $1 \mathrm{~min} / 2200 \mathrm{~g} / 4^{\circ} \mathrm{C}, 3.27 \mathrm{~mL}$ of supernatant were taken off such as $500 \mu \mathrm{L}$ remain in the tube. On ice, $195 \mathrm{U}$ of ligase (T4 DNA ligase, NEB M0202L) were carefully mixed and re-suspended with the pellet, then incubated overnight at $16^{\circ} \mathrm{C}$. After incubation this sample corresponds to $3 \mathrm{C}$ library. Step 4: Reversal of crosslinking. $3 \mathrm{C}$ libraries were 7 times diluted in 2X Proteinase K buffer (5 mM EDTA pH 8.0; $10 \mathrm{mM}$ Tris-HCl pH 8.0; 0.5\% SDS) and water. Undigested and digested samples were supplemented with $500 \mu \mathrm{L}$ of 1xPK buffer. $100 \mu \mathrm{g}$ or $20 \mu \mathrm{g}$ of proteinase $\mathrm{K}(20 \mathrm{mg} / \mathrm{mL})$ were mixed to the $3 \mathrm{C}$ libraries or to the undigested and digested DNA, respectively. All samples were incubated during $1 \mathrm{~h}$ at $50^{\circ} \mathrm{C}$ and then during $4 \mathrm{~h}$ at $65^{\circ} \mathrm{C}$ to reverse the crosslinking reaction. Step 5: DNA purification. 1 volume of Phenol:Chloroform:IAA was added to each sample (i.e., $4 \mathrm{~mL}$ to $3 \mathrm{C}$ library and $500 \mu \mathrm{L}$ to the undigested and digested samples) and vigorously mixed. Following a centrifugation $10 \mathrm{~min} / 16,100 \mathrm{~g} / \mathrm{RT}$, the supernatant aqueous phase was recovered in a new tube. 2 volumes of absolute ethanol and $\mathrm{NaCl}$ to a final concentration of $250 \mathrm{mM}$ were added to each sample, mixed and let at $-20^{\circ}$ overnight to precipitate DNA. Following a centrifugation $20 \mathrm{~min} / 16,100 \mathrm{~g} / 4^{\circ} \mathrm{C}$, pellets were washed with $70 \%$ ethanol and finally re-suspended in water $(150 \mu \mathrm{L}$ for $3 \mathrm{C}$ libraries; $60 \mu \mathrm{L}$ for the undigested and digested samples). Step 6: Qualitative PCR. After quantification at Nanodrop spectrophotometer, qualitative PCR (HiFi-Taq polymerase ${ }^{\mathrm{TM}}$ kit, Life Technologies, 11304-011) was carried out on 50 ng DNA of each samples by using the following primer pairs: Promoter-Gene, to detect genomic DNA (loading control); Promoter-Enhancer 
site, to detect the predicted interaction ( $3 \mathrm{C}$ products); Promoter-Enhancer nearby genomic region, as a negative control (non-interacting regions). Validated primers on $P 2 R Y 2$ gene-enhancer interaction were used as a technique positive control [41] and custom primers were used to study DSCAM-AS1 promoter-enhancer interaction. Primers are reported in Supplemental Table S6. PCR products were checked on $2 \%$ agarose-gel.

Supplementary Materials: Supplementary materials can be found at www.mdpi.com/1422-0067/19/2/593/s1.

Acknowledgments: We thank Salvatore Oliviero from Italian Institute for Genomic Medicine (IIGM, Torino, Italy) for the RNAseq experiment carried out in his laboratory. This work was supported by Associazione Italiana per la Ricerca sul Cancro [Grant IG 15600 to MDB]; by Fondazione CRT [grants 2014.1854 and 2017.0823 to MDB]; by University of Torino [2014 Local Research funding to MDB]. We thank Mauro Filisetti for graphic abstract design.

Author Contributions: Valentina Miano, Giulio Ferrero, and Michele De Bortoli conceived and designed the experiments; Valentina Miano, Valentina Rosti, and Eleonora Manitta performed the experiments; Giulio Ferrero and Jamal Elhasnaoui performed computational analyses; Giulia Basile helped with RNA-seq libraries preparation; Giulio Ferrero, Valentina Miano, and Michele De Bortoli wrote the paper.

Conflicts of Interest: The authors declare no conflict of interest.

\section{Abbreviations}

$\begin{array}{ll}\text { SE } & \text { Super Enhancer } \\ \text { TSS } & \text { Transcription Start Site } \\ \text { ER } \alpha & \text { Estrogen Receptor } \alpha \\ \text { aERBS } & \text { ApoER } \alpha \text { Binding Site } \\ \text { SE-aERBS } & \text { ApoER } \alpha \text { Binding Site associated to a Super Enhancer region } \\ \text { 3C } & \text { Chromatin Conformation Capture } \\ \text { ChIA-PET } & \text { Chromatin Interaction Analysis with Paired-End-Tag sequencing } \\ \text { GRO-Seq } & \text { Global Run-On Sequencing } \\ \text { HD } & \text { Hormone Deprived Medium } \\ \text { E2 } & \text { 17ß-estradiol } \\ \text { DE } & \text { Differentially Expressed } \\ \text { LTED } & \text { Long-Term Estrogen Deprived cells } \\ \text { AIs } & \text { Aromatase Inhibitors }\end{array}$

\section{References}

1. Davies, E.; Hiscox, S. New therapeutic approaches in breast cancer. Maturitas 2011, 68, 121-128. [CrossRef] [PubMed]

2. Barroso-Sousa, R.; Silva, D.D.A.F.R.; Alessi, J.V.M.; Mano, M.S. Neoadjuvant endocrine therapy in breast cancer: Current role and future perspectives. Ecancermedicalscience 2016, 10, 609. [CrossRef] [PubMed]

3. Oseni, T.; Patel, R.; Pyle, J.; Jordan, V.C. Selective estrogen receptor modulators and phytoestrogens. Planta Med. 2008, 74, 1656-1665. [CrossRef] [PubMed]

4. Chumsri, S.; Howes, T.; Bao, T.; Sabnis, G.; Brodie, A. Aromatase, aromatase inhibitors, and breast cancer. J. Steroid Biochem. Mol. Biol. 2011, 125, 13-22. [CrossRef] [PubMed]

5. Clarke, R.; Tyson, J.J.; Dixon, J.M. Endocrine resistance in breast cancer-An overview and update. Mol. Cell. Endocrinol. 2015, 418, 220-234. [CrossRef] [PubMed]

6. Caizzi, L.; Ferrero, G.; Cutrupi, S.; Cordero, F.; Ballaré, C.; Miano, V.; Reineri, S.; Ricci, L.; Friard, O.; Testori, A.; Corà, D.; Caselle, M.; Di Croce, L.; De Bortoli, M. Genome-wide activity of unliganded estrogen receptor- $\alpha$ in breast cancer cells. Proc. Natl. Acad. Sci. U.S.A. 2014, 111, 4892-4897. [CrossRef] [PubMed]

7. Arnal, J.-F.; Lenfant, F.; Metivier, R.; Flouriot, G.; Henrion, D.; Adlanmerini, M.; Fontaine, C.; Gourdy, P.; Chambon, P.; Katzenellenbogen, B.; Katzenellenbogen, J. Membrane and Nuclear Estrogen Receptor Alpha Actions: From Tissue Specificity to Medical Implications. Physiol. Rev. 2017, 97, 1045-1087. [CrossRef] [PubMed]

8. Hah, N.; Murakami, S.; Nagari, A.; Danko, C.G.; Lee Kraus, W. Enhancer transcripts mark active estrogen receptor binding sites. Genome Res. 2013, 23, 1210-1223. [CrossRef] [PubMed] 
9. Pott, S.; Lieb, J.D. What are super-enhancers? Nat. Publ. Gr. 2015. [CrossRef] [PubMed]

10. Hnisz, D.; Abraham, B.J.; Lee, T.I.; Lau, A.; Saint-André, V.; Sigova, A.A.; Hoke, H.A.; Young, R.A. Super-enhancers in the control of cell identity and disease. Cell 2013, 155, 934-947. [CrossRef] [PubMed]

11. Hnisz, D.; Schuijers, J.; Lin, C.Y.; Weintraub, A.S.; Abraham, B.J.; Lee, T.I.; Bradner, J.E.; Young, R.A. Convergence of developmental and oncogenic signaling pathways at transcriptional super-enhancers. Mol. Cell 2015, 58, 362-370. [CrossRef] [PubMed]

12. Blinka, S.; Reimer, M.H.; Pulakanti, K.; Rao, S. Super-enhancers at the nanog locus differentially regulate neighboring pluripotency-associated genes. Cell Rep. 2016, 17, 19-28. [CrossRef] [PubMed]

13. Wang, S.; Zang, C.; Xiao, T.; Fan, J.; Mei, S.; Qin, Q.; Wu, Q.; Li, X.; Xu, K.; He, H.H.; Brown, M.; Meyer, C.A.; Liu, X.S. Modeling cis-regulation with a compendium of genome-wide histone H3K27ac profiles. Genome Res. 2016, 26, 1417-1429. [CrossRef] [PubMed]

14. Bojcsuk, D.; Nagy, G.; Balint, B.L. Inducible super-enhancers are organized based on canonical signal-specific transcription factor binding elements. Nucleic Acids Res. 2017, 45, 3693-3706. [CrossRef] [PubMed]

15. Derrien, T.; Johnson, R.; Bussotti, G.; Tanzer, A.; Djebali, S.; Tilgner, H.; Guernec, G.; Martin, D.; Merkel, A.; Knowles, D.G.; et al. The GENCODE v7 catalog of human long noncoding RNAs: Analysis of their gene structure, evolution, and expression. Genome Res. 2012, 22, 1775-1789. [CrossRef] [PubMed]

16. Schmitt, A.M.; Chang, H.Y. Long noncoding RNAs: At the intersection of cancer and chromatin biology. Cold Spring Harb. Perspect. Med. 2017, 7. [CrossRef] [PubMed]

17. Iyer, M.K.; Niknafs, Y.S.; Malik, R.; Singhal, U.; Sahu, A.; Hosono, Y.; Barrette, T.R.; Prensner, J.R.; Evans, J.R.; Zhao, S.; et al. The landscape of long noncoding RNAs in the human transcriptome. Nat. Genet. 2015, 47, 199-208. [CrossRef] [PubMed]

18. Shore, A.N.; Rosen, J.M. Regulation of mammary epithelial cell homeostasis by lncRNAs. Int. J. Biochem. Cell Biol. 2014, 54, 318-330. [CrossRef] [PubMed]

19. Hah, N.; Danko, C.G.; Core, L.; Waterfall, J.J.; Siepel, A.; Lis, J.T.; Kraus, W.L. A rapid, extensive, and transient transcriptional response to estrogen signaling in breast cancer cells. Cell 2011, 145, 622-634. [CrossRef] [PubMed]

20. Jonsson, P.; Coarfa, C.; Mesmar, F.; Raz, T.; Rajapakshe, K.; Thompson, J.F.; Gunaratne, P.H.; Williams, C. Single-molecule sequencing reveals estrogen-regulated clinically relevant lncrnas in breast cancer. Mol. Endocrinol. 2015, 29, 1634-1645. [CrossRef] [PubMed]

21. Miano, V.; Ferrero, G.; Reineri, S.; Caizzi, L.; Annaratone, L.; Ricci, L.; Cutrupi, S.; Castellano, I.; Cordero, F.; de Bortoli, M. Luminal long non-coding RNAs regulated by estrogen receptor alpha in a ligand-independent manner show functional roles in breast cancer. Oncotarget 2016, 7, 3201-3216. [CrossRef] [PubMed]

22. Niknafs, Y.S.; Han, S.; Ma, T.; Speers, C.; Zhang, C.; Wilder-Romans, K.; Iyer, M.K.; Pitchiaya, S.; Malik, R.; Hosono, Y.; et al. The lncRNA landscape of breast cancer reveals a role for DSCAM-AS1 in breast cancer progression. Nat. Commun. 2016, 7, 12791. [CrossRef] [PubMed]

23. Theodorou, V.; Stark, R.; Menon, S.; Carroll, J.S. GATA3 acts upstream of FOXA1 in mediating ESR1 binding by shaping enhancer accessibility. Genome Res. 2013, 23, 12-22. [CrossRef] [PubMed]

24. Whyte, W. a.; Orlando, D. a.; Hnisz, D.; Abraham, B.J.; Lin, C.Y.; Kagey, M.H.; Rahl, P.B.; Lee, T.I.; Young, R.A. Master transcription factors and mediator establish super-enhancers at key cell identity genes. Cell 2013, 153, 307-319. [CrossRef] [PubMed]

25. Honkela, A.; Peltonen, J.; Topa, H.; Charapitsa, I.; Matarese, F.; Grote, K.; Stunnenberg, H.G.; Reid, G.; Lawrence, N.D.; Rattray, M. Genome-wide modeling of transcription kinetics reveals patterns of RNA production delays. Proc. Natl. Acad. Sci. U.S.A. 2015, 112, 13115-13120. [CrossRef] [PubMed]

26. Dunham, I.; Kundaje, A.; Aldred, S.F.; Collins, P.J.; Davis, C.A.; Doyle, F.; Epstein, C.B.; Frietze, S.; Harrow, J.; Kaul, R.; Khatun, J.; et al. An integrated encyclopedia of DNA elements in the human genome. Nature 2012, 489, 57-74. [CrossRef] [PubMed]

27. Ferrero, G.; Miano, V.; Beccuti, M.; Balbo, G.; De Bortoli, M.; Cordero, F. Dissecting the genomic activity of a transcriptional regulator by the integrative analysis of omics data. Sci. Rep. 2017, 7, 8564.

28. Li, W.; Notani, D.; Ma, Q.; Tanasa, B.; Nunez, E.; Chen, A.Y.; Merkurjev, D.; Zhang, J.; Ohgi, K.; Song, X.; Oh, S.; Kim, H.-S.; Glass, C.K.; Rosenfeld, M.G. Functional roles of enhancer RNAs for oestrogen-dependent transcriptional activation. Nature 2013, 498, 516-520. [CrossRef] [PubMed] 
29. Schmidt, D.; Schwalie, P.C.; Ross-Innes, C.S.; Hurtado, A.; Brown, G.D.; Carroll, J.S.; Flicek, P.; Odom, D.T. A CTCF-independent role for cohesin in tissue-specific transcription. Genome Res. 2010, 20, 578-588. [CrossRef] [PubMed]

30. Su, Y.; Subedee, A.; Bloushtain-Qimron, N.; Savova, V.; Krzystanek, M.; Li, L.; Marusyk, A.; Tabassum, D.P.; Zak, A.; Flacker, M.J.; Li, M.; et al. Somatic cell fusions reveal extensive heterogeneity in basal-like breast cancer. Cell Rep. 2015, 11, 1549-1563. [CrossRef] [PubMed]

31. Nguyen, V.T.M.; Barozzi, I.; Faronato, M.; Lombardo, Y.; Steel, J.H.; Patel, N.; Darbre, P.; Castellano, L.; Győrffy, B.; Woodley, L.; Meira, A.; Patten, D.K.; Vircillo, V.; Periyasamy, M.; Ali, S.; Frige, G.; Minucci, S.; Coombes, R.C.; Magnani, L. Differential epigenetic reprogramming in response to specific endocrine therapies promotes cholesterol biosynthesis and cellular invasion. Nat. Commun. 2015, 6, 10044. [CrossRef] [PubMed]

32. Jansen, M.P.H.M.; Knijnenburg, T.; Reijm, E.A.; Simon, I.; Kerkhoven, R.; Droog, M.; Velds, A.; van Laere, S.; Dirix, L.; Alexi, X.; Foekens, J.A.; Wessels, L.; Linn, S.C.; Berns, E.M.J.J.; Zwart, W. Hallmarks of aromatase inhibitor drug resistance revealed by epigenetic profiling in breast cancer. Cancer Res. 2013, 73, 6632-6641. [CrossRef] [PubMed]

33. De Wit, E.; de Laat, W. A decade of 3C technologies: insights into nuclear organization. Genes Dev. 2012, 26, 11-24. [CrossRef] [PubMed]

34. Lanz, R.B.; Jericevic, Z.; Zuercher, W.J.; Watkins, C.; Steffen, D.L.; Margolis, R.; McKenna, N.J. Nuclear receptor signaling atlas (www.nursa.org): Hyperlinking the nuclear receptor signaling community. Nucleic Acids Res. 2006, 34, D221-D226. [CrossRef] [PubMed]

35. Laganière, J.; Deblois, G.; Giguère, V. Functional genomics identifies a mechanism for estrogen activation of the retinoic acid receptor alpha1 gene in breast cancer cells. Mol. Endocrinol. 2005, 19, 1584-1592. [CrossRef] [PubMed]

36. Vo, N.; Goodman, R.H. CREB-binding protein and p300 in transcriptional regulation. J. Biol. Chem. 2001, 276, 13505-13508. [CrossRef] [PubMed]

37. Visel, A.; Blow, M.J.; Li, Z.; Zhang, T.; Akiyama, J.A.; Holt, A.; Plajzer-Frick, I.; Shoukry, M.; Wright, C.; Chen, F.; Afzal, V.; Ren, B.; Rubin, E.M.; Pennacchio, L.A. ChIP-seq accurately predicts tissue-specific activity of enhancers. Nature 2009, 457, 854-858. [CrossRef] [PubMed]

38. Wang, X.; Li, S. Chromatin immunoprecipitation-sequencing predicts p300 binding sites in the MCF7 human breast cancer cell line. Int. J. Mol. Med. 2015, 35, 973-978. [CrossRef] [PubMed]

39. Eeckhoute, J.; Keeton, E.K.; Lupien, M.; Krum, S.A.; Carroll, J.S.; Brown, M. Positive cross-regulatory loop ties GATA-3 to estrogen receptor $\alpha$ expression in breast cancer. Cancer Res. 2007, 67, 6477-6483. [CrossRef] [PubMed]

40. Orso, F.; Cottone, E.; Hasleton, M.D.; Ibbitt, J.C.; Sismondi, P.; Hurst, H.C.; de Bortoli, M. Activator protein-2gamma (AP-2gamma) expression is specifically induced by oestrogens through binding of the oestrogen receptor to a canonical element within the 5'-untranslated region. Biochem. J. 2004, 377, 429-438. [CrossRef] [PubMed]

41. Fullwood, M.J.; Wei, C.L.; Liu, E.T.; Ruan, Y. Next-generation DNA sequencing of paired-end tags (PET) for transcriptome and genome analyses. Genome Res. 2009, 19, 521-532. [CrossRef] [PubMed]

42. Chan, C.S.; Song, J.S. CCCTC-binding factor confines the distal action of estrogen receptor. Cancer Res. 2008, 68, 9041-9049. [CrossRef] [PubMed]

43. Fiorito, E.; Sharma, Y.; Gilfillan, S.; Wang, S.; Singh, S.K.; Satheesh, S.V.; Katika, M.R.; Urbanucci, A.; Thiede, B.; Mills, I.G.; Hurtado, A. CTCF modulates estrogen receptor function through specific chromatin and nuclear matrix interactions. Nucleic Acids Res. 2016, 44, 10588-10602. [CrossRef] [PubMed]

44. Hurtado, A.; Holmes, K.A.; Ross-Innes, C.S.; Schmidt, D.; Carroll, J.S. FOXA1 is a key determinant of estrogen receptor function and endocrine response. Nat. Genet. 2011, 43, 27-33. [CrossRef] [PubMed]

45. Carleton, J.B.; Berrett, K.C.; Gertz, J. Multiplex enhancer interference reveals collaborative control of gene regulation by estrogen receptor $\alpha$-bound enhancers. Cell Syst. 2017, 5, 333-344.e5. [CrossRef] [PubMed]

46. Lombardo, Y.; Faronato, M.; Filipovic, A.; Vircillo, V.; Magnani, L.; Coombes, R.C. Nicastrin and Notch4 drive endocrine therapy resistance and epithelial to mesenchymal transition in MCF7 breast cancer cells. Breast Cancer Res. 2014, 16, R62. [CrossRef] [PubMed] 
47. Ross-innes, C.S.; Stark, R.; Teschendorff, A.E.; Holmes, K.A.; Raza, H.; Dunning, M.J.; Brown, G.D.; Gojis, O.; Ellis, I.O.; Andrew, R.; et al. Differential oestrogen receptor binding is associated with clinical outcome in breast cancer. Nature 2012, 481, 389-393. [CrossRef] [PubMed]

48. Kim, D.; Pertea, G.; Trapnell, C.; Pimentel, H.; Kelley, R.; Salzberg, S.L. TopHat2: Accurate alignment of transcriptomes in the presence of insertions, deletions and gene fusions. Genome Biol. 2013, 14, R36. [CrossRef] [PubMed]

49. Liao, Y.; Smyth, G.K.; Shi, W. FeatureCounts: An efficient general purpose program for assigning sequence reads to genomic features. Bioinformatics 2014, 30, 923-930. [CrossRef] [PubMed]

50. Love, M.I.; Huber, W.; Anders, S. Moderated estimation of fold change and dispersion for RNA-seq data with DESeq2. Genome Biol. 2014, 15, 550. [CrossRef] [PubMed]

51. Nueda, M.J.; Tarazona, S.; Conesa, A. Next maSigPro: updating maSigPro bioconductor package for RNA-seq time series. Bioinformatics 2014, 30, 1-5. [CrossRef] [PubMed]

52. Kuleshov, M.V.; Jones, M.R.; Rouillard, A.D.; Fernandez, N.F.; Duan, Q.; Wang, Z.; Koplev, S.; Jenkins, S.L.; Jagodnik, K.M.; Lachmann, A.; et al. Enrichr: A comprehensive gene set enrichment analysis web server 2016 update. Nucleic Acids Res. 2016, 44, W90-W97. [CrossRef] [PubMed]

53. Langmead, B.; Salzberg, S.L. Fast gapped-read alignment with Bowtie 2. Nat. Methods 2012, 9, 357-359. [CrossRef] [PubMed]

54. Zhang, Y.; Liu, T.; Meyer, C.A.; Eeckhoute, J.; Johnson, D.S.; Bernstein, B.E.; Nusbaum, C.; Myers, R.M.; Brown, M.; Li, W.; et al. Model-based analysis of ChIP-Seq (MACS). Genome Biol. 2008, 9, R137. [CrossRef] [PubMed]

55. Zhou, X.; Wang, T. Using the wash U epigenome browser to examine genome-wide sequencing data. Curr. Protoc. Bioinforma. 2012. Chapter 10, Unit 10.10. [CrossRef]

56. Quinlan, A.R.; Hall, I.M. BEDTools: A flexible suite of utilities for comparing genomic features. Bioinformatics 2010, 26, 841-842. [CrossRef] [PubMed]

(C) 2018 by the authors. Licensee MDPI, Basel, Switzerland. This article is an open access article distributed under the terms and conditions of the Creative Commons Attribution (CC BY) license (http:/ / creativecommons.org/licenses/by/4.0/). 